\title{
Synthesis and Screening of Substituted Thiadiazoles Against Gleophyllum Straitum
}

\author{
M.G.H.Zaidi ${ }^{*}$, Seema Zaidi ${ }^{2}$, I.P.Pandey ${ }^{2}$ and \\ ${ }^{1}$ Department of Chemistry, C.B.S.H, Govind Ballabh Pant University of Agriculture and \\ TechnologyPantnagar-263145, Udham Singh Nagar, Uttaranchal, INDIA \\ ${ }^{2}$ Department of Chemistry DAV Post Graduate College Dehradun \\ Affiliated to H.N.B. University Garhwal INDIA \\ E-Mail:mgh_Zaidi@yahoo.com
}

Received 30 March 2004; Accepted 1 May 2004

\begin{abstract}
Cyclocondensation of a series of substituted phenoxy methylene carboxylic acids with thiosemoicarbazides afforded 2-Amino-5-Aryloxy Methylene -1,3,4 Thiadiazoles (la-le). The later were subsequently condensed with different phenoxymethylene carboxylic acid chlorides into 2- Aryloxy Methyleneamido-5Aryloxy Methylene-1,3,4-Thiadiazoloyl Amides. The wood preservation efficiency of the both class of compounds was evaluated against a wood rotting fungus Gleophyllum Straitum at different concentrations using food poison technique. In general phenoxy derivatives have shown more control over the growth of Gleophyllum Straitum than their corresponding aminothiadiazoles at $500 \mathrm{ppm}$. The chlorophenoxy-substituted thiadiazoles among all have shown more activity then others against Gleophyllum Straitum.
\end{abstract}

Key words: Substituted Thiadiazoles, Gleophyllum Straitum, fungicidal activity

\section{Introduction}

The life of wood under applications continuously deteriorates due to fluctuations in temperature and humidity. Such environmental factors promote the growth of decay microorganisms like fungi and bacteria; attack of animals and insects over wood that reduce the thermal and mechanical performance of this material. Invasion caused by fungi, boring insects: termites, beetles etc alter the physical and chemical characteristics of wood. Due to such reasons, wood had always been targeted for its surface and bulk modifications. The type and nature of modifications imposed over wood are based on its application and environmental factors. In recent years a variety of hetrocyclic systems, 
inorganic compounds and polymers with antifungal characteristics were searched as a potential wood preservatives $^{1}$.

Chemical treatment to low grade wood with acetic anhydride has been reported to affect the strength of wood due to the formation of acetic acid, but the post treatments of wood with aniline have imparted termite and fungal resistance in woods ${ }^{2}$. Application of copper sulphate as one of the additive in the synthesis of wood polymer composites from polystyrene, polymethyl methacrylate, polybutyl methacrylate woods in presence of varying amounts of acryl amide have shown increased insect resistance ${ }^{3}$. Treatment with bioactive polymers has been reported to enhance the resistance of wood towards decay fungi. Such bioactive polymers are either formed by condensation of bioactive groups into the polymer or grafting them to polymer or by synthesizing bioactive monomer and polymerizing it insitu in the cell walls derivatives Graft co polymerizations of Organotin polymers in wood imparted substantial toxicity to wood towards marine fouling agents and wood decay organism like brown and white rot fungi respectively ${ }^{4}$.

The role of such bioactive polymers as wood preservative is very limited, as they do not impart high service life to wood under accelerated weather conditions. The applications of high molecular mass thermoplastic polymers as wood modifiers supersede over such bioactive

polymers because the former impart appreciable mechanical and thermal stabilities along with substantial water resistance to a variety of wood but do not account for wood preservation against deteriorating fungi. In such cases, therefore need of suitable wood preservative that could be utilized along with thermoplastic materials is proved to be essential. An extensive literature survey reveled that no such attempt has been made to study the efficiency of the hetrocyclic compounds as wood preservatives against deteriorating fungi. With this view in mind and in continuation of earlier work tow ards the search for new fungicides ${ }^{5}$, the present investigation has been made and directed tow ards the synthesis of the proposed heterocyclic compounds and to study their activity against the proposed wood deteriorating fungus Gleophyllum straitum using food poison technique.

\section{Experimental Section}

\section{Starting materials}

All the chemicals and solvents were purchased from S.D.Fine chemicals India. The compounds synthesized were obtained in high purity by TLC, using silica gel as absorbent and iodine as visualizing agent .The structure of compounds were ascertained by IR $(\mathrm{KBr})$ spectra scanned on Perkin Elmer - 157 and NMR spectra on Varian 60D using TMS as internal standard. The chemical shift has been recorded in terms value.

\section{Phenoxy acetic acids}

A series of phenoxy acetic acids from various substituted phenols were prepared by the slight modification by us made earlier ${ }^{6}$. In general the phenoxy acetic acids were synthesized under the following reaction condition that has provided their satisfactory yields. A mixture of substituted phenol $(0.01 \mathrm{~mol})$ and sodium hydroxide $(0.03 \mathrm{~mol})$ was dissolved in appropriate quantity of aqueous chloro acetic acid (50\%) and refluxed for 2 to 4 hours. It was cooled and extracted with ether (90 ml) the ethanol layer was washed with water $(10 \mathrm{ml})$. The solid thus precipitated was shaked with aqueous sodium bicarbonate $(5 \% 60 \mathrm{ml})$ and acidified with concentrated $\mathrm{HQ}$. The compounds isolated were crystallized from water. 


\section{2-Amino-5-Aryloxy Methylene -1,3,4 Thiadiazoles.}

The mixture containing either of the thiosemicarbazides $(0.01 \mathrm{~mol})$ and substituted phenoxy acid $(0.01$ mol) in presence of conc.sulphuric acid (sp. gr. 1.81) was fused at $60-80^{\circ} \mathrm{C}$ in a two necked flask equipped with a reflux condenser and nitrogen circulation tap for 4 hours. The products were isolated in ice-cold water followed by neutralization with ammonium hydroxide $(28 \%)$. The solid thus obtained were filtered, crystallized from ethanol and dried below $50^{\circ} \mathrm{C}$.The analytical data of synthesized compounds are summarized (Table 1)

Table-1. 2-Amino-5-Aryloxy Methylene -1,3,4 Thiadiazoles

\begin{tabular}{ccccccc}
\hline S.No & $\mathrm{R}$ & Mol. Formula & Yield & $\begin{array}{c}\mathrm{Mp} \\
{ }^{0} \mathrm{C}\end{array}$ & \multicolumn{2}{c}{$\begin{array}{c}\text { Nitrogen (\%) Calc. } \\
\text { Found }\end{array}$} \\
\hline la & $\mathrm{p}-\mathrm{C}-\mathrm{C}_{6} \mathrm{H}_{4}$ & $\mathrm{C}_{9} \mathrm{H}_{8} \mathrm{CN}_{3} \mathrm{SO}$ & 68 & 131 & 17.39 & 17.28 \\
Ib & $0-\mathrm{CH}_{3}=\mathrm{C}_{6} \mathrm{H}_{4}$ & $\mathrm{C}_{10} \mathrm{H}_{11} \mathrm{~N}_{3} \mathrm{SO}$ & 47 & 146 & 19.00 & 18.98 \\
Ic & $\mathrm{m}-\mathrm{CH}_{3}-\mathrm{C}_{6} \mathrm{H}_{4}$ & $\mathrm{C}_{10} \mathrm{H}_{11} \mathrm{~N}_{3} \mathrm{SO}$ & 50 & 168 & 19.00 & 18.30 \\
Id & $\mathrm{p}-\mathrm{CH}_{3}-\mathrm{C}_{6} \mathrm{H}_{4}$ & $\mathrm{C}_{10} \mathrm{H}_{11} \mathrm{~N}_{3} \mathrm{SO}$ & 56 & 156 & 19.00 & 18.91 \\
le & $\mathrm{p}-\mathrm{C}_{10} \mathrm{H}_{7}$ & $\mathrm{C}_{13} \mathrm{H}_{11} \mathrm{~N}_{3} \mathrm{SO}$ & 42 & 172 & 10.37 & 10.42 \\
\hline
\end{tabular}

\section{2- Aryloxy Methyleneamido-5-Aryloxy Methylene-1,3,4-Thiadiazoloyl Amides}

Solution of 2-Amino-5-Aryloxy Methylene $-1,3,4$ Thiadiazoles $(0.01 \mathrm{~mol})$ in dry $\mathrm{N}, \mathrm{N}$-dimethyl acetamide $(50 \mathrm{~mL})$ was cooled at $-10^{\circ} \mathrm{C}$.To this was added freshly synthesized solution of the substituted acid chlorides in dry $\mathrm{N}$, N-dimethyl acetamide $(50 \mathrm{~mL}, 0.02 \mathrm{M})$ with constant stirring for $2 \mathrm{hr}$. The highly viscous solution was then poured into ice cooled water, where 2- Aryloxy Methyleneamido-5-Aryloxy Methylene-1,3,4-Thiadiazoloyl Amides were precipitated. The crude products was crystallized from absolute alcohol.<smiles>[R]OCc1[X]c(NC=O)[nH]n1</smiles> 


\section{Fungicidal screening}

Food poison technique was applied to investigate the efficacy of synthesized compounds against Gleophyllum straitum, using. Malt extract medium was prepared by mixing $20 \mathrm{gm}$ malt extract, $20 \mathrm{gm}$ agar in 1-liter water at the $\mathrm{pH}$ of 6.5. The prepared medium was sterilized in an autoclave at $15 \mathrm{lbs}$ psi for $30 \mathrm{~min}$. commercially available streptomycin antibiotic was then added into the media before preparing the plates to check the bacterial contamination. The lyophilized culture of above fungus was routinely grown and maintained in malt extract medium. The evaluation of efficacy of test compounds had also been made in malt extract medium. Medium $(20 \mathrm{ml})$ was then poured in sterilized petri plates and suspension of lyophilized culture in water was inoculated on the solidified plates. These plates were incubated in upside up position in a BOD incubator at $25^{\circ} \mathrm{C}$ for 10 days. Pure culture was maintained on malt extracts slants.

The effect of synthesized compounds on the control of radial growth of the fungal was studied by incorporating their test solutions at 500-ppm concentration. The plates were inoculated with fungus taken from revived culture. Inoculum of 5-mm. discs was inoculated by cutting from the edge of 10 days old culture with the help of steel cork borer. Inoculated plates were incubated at $25^{\circ} \mathrm{C}$ for 10 days. Inoculated plates without any test compound were served as control. Radial growth of fungus was measured with the help of scale. Inhibition percentage was calculated as C-T/CX100 where, $\mathrm{C}=$ diameter of fungal mycelium in control and $\mathrm{T}=$ diameter of fungal mycelium in treated plate.

\section{Results and Discussion}

The various physico-chemical and analytical data of thiadiazoles and oxa thiadiazoles has been summarized in (Table I). All such compounds synthesized have shown their satisfactory yields. The structure of compounds was confirmed through their micro analytical and spectral data. IR spectra of compounds indicated absorption ranges at $3300-3200 \mathrm{~cm}^{-1} \mathrm{v}(\mathrm{NH}), 1260-1040 \mathrm{~cm}^{-1} \mathrm{v}$ and $1630-1615 \mathrm{~cm}^{-1}$ corresponding to the presence of respective groups in the compounds. These spectral data are sufficient to confirm the presence of cyclic - $\mathrm{NH}$ - group, $\mathrm{C}-\mathrm{o}-\mathrm{c}$ (ether linkage) in mentioned compounds. PMR spectra of some selected compounds $(1, \mathrm{VII}$, and $\mathrm{XI})$ in $\&\left(\mathrm{CDO}_{3}\right)$ using TMS as internal standard has been recorded. Their characteristic signals were observed in the range of 7.2-8.5(Br NH), 6.2-7.8(m $\mathrm{Ar} \mathrm{H})$ and 4.9-5.9 $\left(2 \mathrm{H}, \mathrm{OCH}_{2}\right)$

The activity of all the synthesized fungicides at 500 ppm, against Gleophyllum straitum was studied and found to be continuously varying with respect to the substituents attached with phenylene nucleus. At lower concentration no significant activity the synthesized compound has been observed In general the compounds (la-le) indicated greater activity than (lla-llt). The compounds containing chloro group at Para position in2-Amino-5-Aryloxy Methylene -1,3,4 Thiadiazoles (Ila-Ild) indicated the activities having intermediate values as those of the fungicides methyl groups and $\hat{a}-\mathrm{C}_{10} \mathrm{H}_{7}$ separately. Further increase in concentration of the test compound may increase the control of the growth of Gleophyllum straitum. A change in the position of substituents also has shown appreciable changes in fungicidal activity of the compounds. The change of in the position of methyl group did not shown any marked effect towards fungicidal activity. Further screening of compounds on a wider range of wood rotting fungi and concentrations are still desirable. The quite low activities of these compounds as wood preservatives render that they could be applied to wood for the control of the grow th of Gleophyllum straitum at very elementary levels.

\section{Conclusion}

In the present work, it is concluded that the synthesized fungicides having thiadiazoles linkage could be applied (500) ppm as wood preservative against the fungus Gleophyllum straitum 


\section{Reference}

1. Rowell M and Rebecca E.I Holzforschung, 200155358

2. $\quad$ Singh D, Dev I and K Satish J. Timber. Div. Assoc. India 199743 (3) 27

3. Khan A M and Ali K M I Polym. Plast. Technol. Eng.. 199635 (6) 959

4. Tyagi Y, Varshney K, Sah P L and Zaidi M G H J. TimberDivAssoc. India, 200349 (1\&2) (In press).

5. Joshi TK and Zaidi M GH Pestology 2003 X X VII (5) 20

6. Yadav V, Yadav L S, Srivastava P and Zaidi M G H Pestology, 2001 X X V (6) 61 


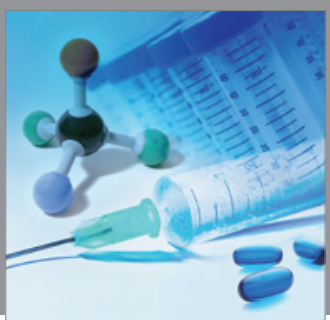

International Journal of

Medicinal Chemistry

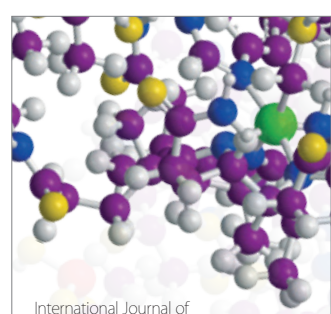

Carbohydrate Chemistry

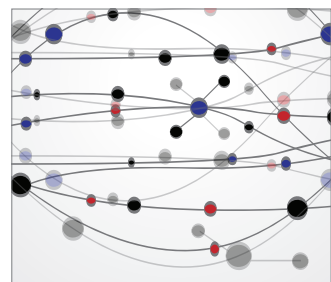

The Scientific World Journal
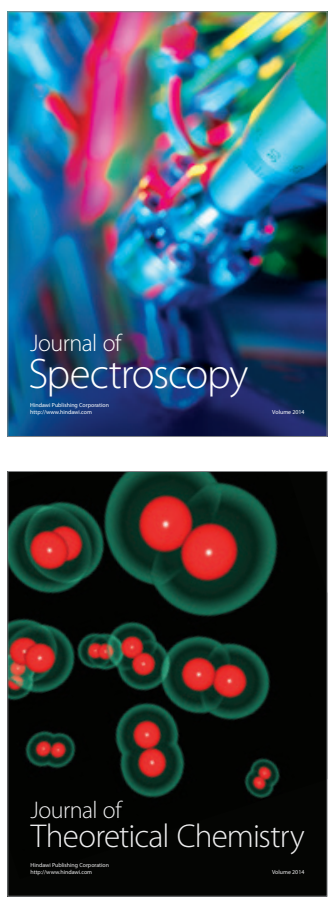
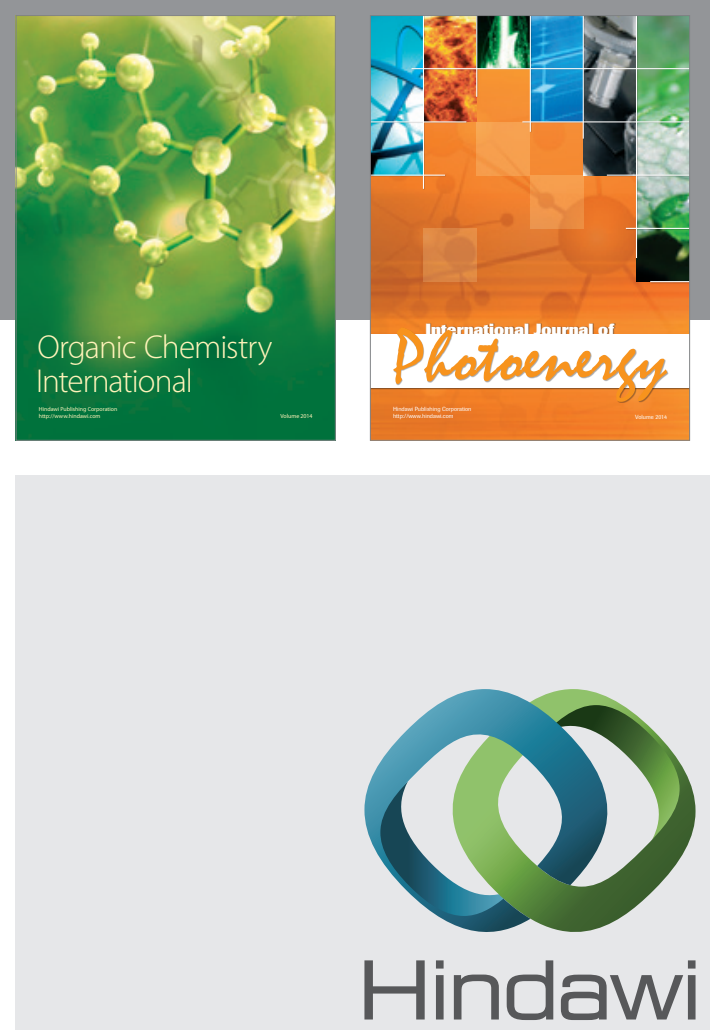

Submit your manuscripts at

http://www.hindawi.com
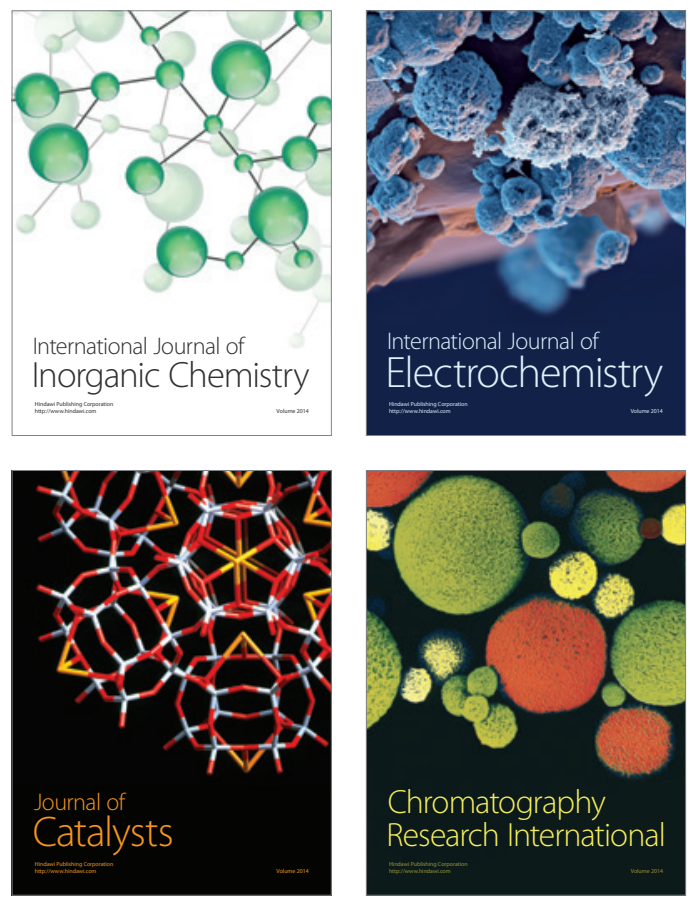
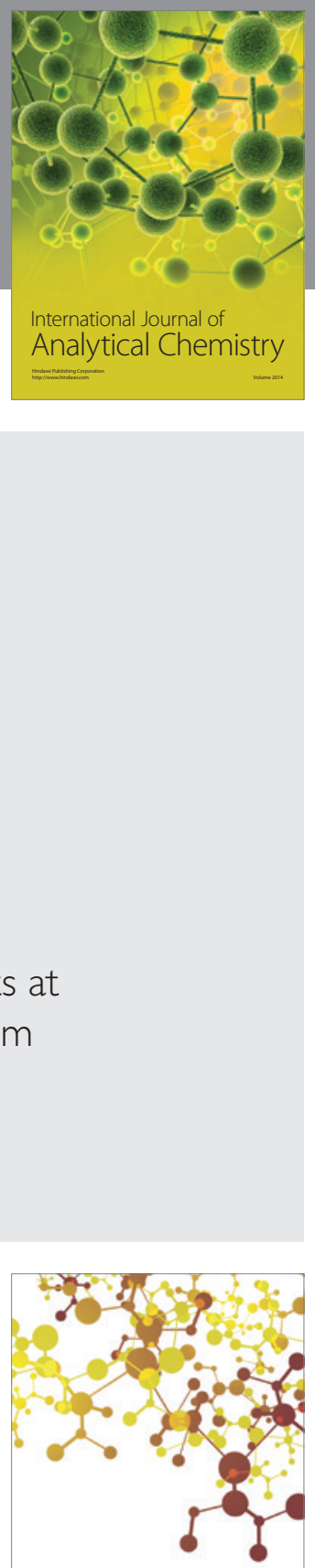

Journal of

Applied Chemistry
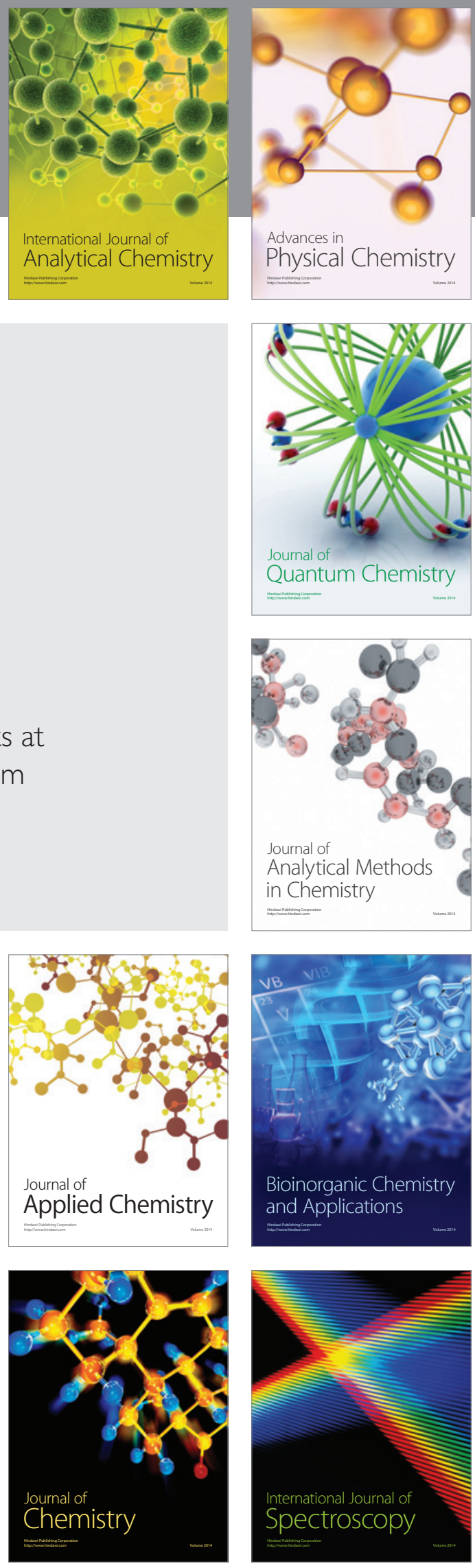